\title{
A dual colour dual fusion fluorescence in situ hybridisation study on the genesis of complex variant translocations in chronic myelogenous leukaemia
}

\author{
CHI-CHIU SO, THOMAS SHEK-KONG WAN, SZE-FAI YIP and LI-CHONG CHAN \\ Department of Pathology, Li Ka Shing Faculty of Medicine, The University of Hong Kong, Hong Kong, P.R. China
}

Received August 31, 2007; Accepted October 22, 2007

\begin{abstract}
Complex variant 9;22 translocations occur in a significant minority of chronic myelogenous leukaemia (CML) patients. Different mechanisms of their formation have been described. We report dual colour dual fusion fluorescence in situ hybridisation data in 12 Chinese CML patients with complex translocations. Three previously reported breakpoint hotspots in a third partner chromosome (14q32, 17q25, 1q21) were observed. In 10/12 (83.3\%) patients, the abnormality occurred as a single step 3-break event. Only a single abnormal clone harbouring the complex translocation was seen in this group. The remaining 2 cases in the chronic phase showed a 4-break mechanism (2/12, 16.7\%). Deletion of 5' $A B L$ at $\operatorname{der}(9)$ was not observed in any of the 12 patients, however, the loss of $3^{\prime} B C R$ was observed in 1 patient $(1 / 12,8.3 \%)$. Together with previous findings, these data suggest that these variant translocations occur more often as a 3-break singlestep process with no reciprocal $A B L-B C R$ fusion. On the other hand, a 4-break event is also regularly seen during the initial stages of leukaemogenesis, which likely predisposes to $\operatorname{der}(9)$ deletion. The observed difference in rates of $\operatorname{der}(9)$ deletion reported in a series of CML patients with variant translocations may be related to a difference in rates of a 4-break event.
\end{abstract}

\section{Introduction}

Complex variant translocation of $(9 ; 22)$ has an incidence of $\sim 10 \%$ in patients with chronic myelogenous leukaemia (CML) $(1,2)$. The most common is a 3 -way balanced $t(9 ; 22 ; \mathrm{v})$. Previous studies using a chromosome 22 painting probe indicated either a one-step (3) or two-step process (4) in the genesis of these variants. Recent studies using the fluorescence in situ hybridisation (FISH) method showed the occurrence

Correspondence to: Dr Chi-Chiu So, Department of Pathology, Li Ka Shing Faculty of Medicine, The University of Hong Kong, Hong Kong, P.R. China

E-mail: scc@pathology.hku.hk

Key words: variant, cytogenetics, chronic myelogenous leukaemia, 9 q34 deletion, Chinese of either mechanism in different and occasionally the same cases $(5,6)$.

Chronic myelogenous leukaemia with der(9) deletion has been shown to carry a poor prognosis (7-10). Complex variant translocations in CML have been reported in many studies to be associated with a significantly higher incidence of der(9) deletion than CML with classical Ph translocation (weighted average 40.4 vs $12.7 \%$ ) (reviewed in ref. 6). These translocations impart a poor survival to this group of patients when compared to CML patients with classical $t(9 ; 22)$ or variant translocations without der(9) deletion (5).

In this study, we employed D-FISH to investigate the mechanism of formation of the most common 3-way $t(9 ; 22 ; \mathrm{v})$ in 12 Chinese patients with CML. The incidence of $\operatorname{der}(9)$ deletion was also determined in this cohort of patients.

\section{Materials and methods}

Clinical samples. A search for complex variant translocation in CML patients was performed in our cytogenetics database. Twelve cases were identified which had available materials for D-FISH analysis - 10 in the chronic phase and 2 in the accelerated phase. All showed a balanced 3-way t $(9 ; 22 ; \mathrm{v})$.

Conventional cytogenetic analysis. Cytogenetic analysis was performed on Giemsa banded ( $\mathrm{G}$ banded) metaphases obtained through short-term synchronised and unsynchronised cultures of bone marrow cells based on standardised protocols. Karyotypes were reported in accordance with ISCN 1995.

$D$-FISH. Detection of $B C R-A B L$ and $A B L-B C R$ gene fusions was performed using $B C R / A B L$ dual colour dual fusion translocation probes (Abbott Molecular/Vysis, Des Plaines, IL), according to the manufacturer's instructions. In total, 300 interphase nuclei on cytospin smears were analysed for the presence of fusion signals. In selected cases, metaphase FISH was performed on $\mathrm{G}$ banded metaphases relocated using microscope coordinates, as described previously (11). A $2 \mathrm{G} 2 \mathrm{O} 1 \mathrm{~F}$ pattern indicated a one-step 3-break event whereas a $1 \mathrm{G} 1 \mathrm{O} 2 \mathrm{~F}$ pattern indicated a two-step 4-break event.

\section{Results}

Table I shows the disease status during the investigation and full karyotype of the 12 cases with balanced 3-way 
Table I. Disease status, full karyotype and D-FISH results.

\begin{tabular}{cllll}
\hline Case No. & Disease phase & Karyotype & D-FISH pattern ${ }^{\mathrm{a}}$ & Interpretation \\
\hline 1 & Chronic & $46, \mathrm{XY}, \mathrm{t}(5 ; 9 ; 22)(\mathrm{q} 31 ; \mathrm{q} 34 ; \mathrm{q} 11.2)[13]$ & $89 \% 2 \mathrm{G} 2 \mathrm{O} 1 \mathrm{~F}$ & 3-break \\
& & & $11 \% 2 \mathrm{G} 2 \mathrm{O}$ & Residual normal cells \\
2 & Chronic & $46, \mathrm{XY}, \mathrm{t}(5 ; 9 ; 22)(\mathrm{q} 31 ; \mathrm{q} 34 ; \mathrm{q} 11.2)[7] / 46, \mathrm{XY}[1]$ & $78 \% 2 \mathrm{G} 2 \mathrm{O} 1 \mathrm{~F}$ & 3-break \\
& & & $22 \% 2 \mathrm{G} 2 \mathrm{O}$ & Residual normal cells \\
3 & Chronic & $46, \mathrm{XX}, \mathrm{t}(9 ; 22 ; 10)(\mathrm{q} 34 ; \mathrm{q} 11.2 ; \mathrm{p} 14)[9]$ & $100 \% 2 \mathrm{G} 2 \mathrm{O} 1 \mathrm{~F}$ & 3 -break \\
4 & Chronic & $46, \mathrm{XX}, \mathrm{t}(9 ; 22 ; 10)(\mathrm{q} 34 ; \mathrm{q} 11.2 ; \mathrm{p} 14)[6]$ & $100 \% 2 \mathrm{G} 2 \mathrm{O} 1 \mathrm{~F}$ & 3 -break \\
5 & Chronic & $46, \mathrm{XY}, \mathrm{t}(9 ; 22 ; 14)(\mathrm{q} 34 ; \mathrm{q} 11.2 ; \mathrm{q} 32.1)[12]$ & $100 \% 2 \mathrm{G} 2 \mathrm{O} 1 \mathrm{~F}$ & 3 -break \\
6 & Chronic & $46, \mathrm{XX}, \mathrm{t}(5 ; 9 ; 22)(\mathrm{p} 15 ; \mathrm{q} 34 ; \mathrm{q} 11.2)[10]$ & $100 \% 2 \mathrm{G} 2 \mathrm{O} 1 \mathrm{~F}$ & 3 -break \\
7 & Chronic & $46, \mathrm{XY}, \mathrm{t}(9 ; 22 ; 17)(\mathrm{q} 34 ; \mathrm{q} 11.2 ; \mathrm{q} 25)[16]$ & $100 \% 2 \mathrm{G} 2 \mathrm{O} 1 \mathrm{~F}$ & 3 -break \\
8 & Chronic & $46, \mathrm{XY}, \mathrm{t}(7 ; 9 ; 22)(\mathrm{q} 35 ; \mathrm{q} 34 ; \mathrm{q} 11.2)[8]$ & $100 \% 2 \mathrm{G} 2 \mathrm{O} 1 \mathrm{~F}$ & 3 -break \\
9 & Accelerated & $46, \mathrm{XY}, \mathrm{t}(9 ; 22 ; 19)(\mathrm{q} 34 ; \mathrm{q} 11.2 ; \mathrm{q} 12.3)[5] / 47, \mathrm{idem},+8[3]$ & $100 \% 2 \mathrm{G} 2 \mathrm{O} 1 \mathrm{~F}$ & 3 -break \\
10 & Accelerated & $46, \mathrm{XX}, \mathrm{t}(1 ; 9 ; 22)(\mathrm{q} 21 ; \mathrm{q} 34 ; \mathrm{q} 11.2)[8]$ & $92 \% 2 \mathrm{G} 2 \mathrm{O} 1 \mathrm{~F}$ & 3 -break \\
& & & $8 \% 2 \mathrm{G} 2 \mathrm{O}$ & Residual normal cells \\
11 & Chronic & $46, \mathrm{XX}, \mathrm{t}(4 ; 9 ; 22)(\mathrm{p} 11 ; \mathrm{q} 34 ; \mathrm{q} 11.2)[16]$ & $19 \% 1 \mathrm{G} 1 \mathrm{O} 2 \mathrm{~F}$ & 4-break \\
& & & $81 \% 1 \mathrm{G} 2 \mathrm{O} 1 \mathrm{~F}$ & Loss of 3' BCR in subclone \\
12 & Chronic & $46, \mathrm{XX}, \mathrm{t}(9 ; 22)(\mathrm{q} 34 ; \mathrm{q} 11.2)[2]$ & $100 \% 1 \mathrm{G} 1 \mathrm{O} 2 \mathrm{~F}$ & 2-break in stemline
\end{tabular}

${ }^{\mathrm{a} D}$-FISH pattern: G, green (BCR, 22q11.2); O, orange (ABL, 9q34); F, fusion (BCR-ABL; $\left.A B L-B C R\right)$.

translocations. Ten patients were in the chronic phase and 2 in the accelerated phase. No patient was in the blast phase. None of them had received tyrosine kinase inhibitor therapy prior to investigation. Residual normal metaphases were detected in only 1 case by conventional cytogenetics. Recurrent breakpoints in a third partner chromosome were observed at 5q11.2 $(\mathrm{n}=2)$ and 10p14 $(\mathrm{n}=2)$. Clonal evolution was evident in 2 cases. Case 9 showed a subclone with additional trisomy 8 at disease acceleration. Case 12 harboured a stem line with classical $\mathrm{t}(9 ; 22)$, which was not seen in any other case in this series.

In 10 cases, D-FISH revealed ( 8 chronic and 2 in the accelerated phase) a $2 \mathrm{G} 2 \mathrm{O} 1 \mathrm{~F}$ pattern indicating a one-step 3-break event. A reciprocal $A B L-B C R$ fusion signal was absent. Normal cells with a $2 \mathrm{G} 2 \mathrm{O}$ pattern were observed in 3 of these 10 cases in significant proportions (8-22\%) of interphase nuclei examined. In the remaining 2 cases of the chronic phase CML, a $1 \mathrm{G} 1 \mathrm{O} 2 \mathrm{~F}$ pattern was seen indicating a two-step 4-break mechanism. This included the only case (Case 12) showing a stemline with classical $t(9 ; 22)$ and another case (Case 11) with a single abnormal clone of variant translocation. Metaphase FISH analysis of these 2 cases showed the presence of a fusion signal on $\operatorname{der}(9)$, indicating an intact $A B L-B C R$ fusion gene and a further break distal to the $A B L$ breakpoint in the 3-way translocation (Fig. 1a, b and c). None of the 12 cases showed a loss of the 5' $A B L$ signal on $\operatorname{der}(9)$, however, the loss of the $3^{\prime} B C R$ signal on $\operatorname{der}(9)$ was observed in a subclone in 1 case (Case 11). The rate of $\operatorname{der}(9)$ deletion was thus $1 / 12(8.3 \%)$.

\section{Discussion}

In CML, the most common form of complex variant translocations is 3 -way balanced $t(9 ; 22 ; \mathrm{v})$. Indirect evidence suggests a one-step process in the formation of these variant translocations in most incidences: i) They are usually observed at initial diagnosis of the chronic phase, although are not normally detected as new cytogenetic abnormalities during disease evolution. ii) By themselves they do not signify disease acceleration. iii) These variants are most often found in the absence of a clone bearing classical $t(9 ; 22)$.

The availability of D-FISH provides a useful tool in investigating the mechanism of the formation of these variant translocations in CML. Using this technique, a 3-break process $(2 \mathrm{G} 2 \mathrm{O} 1 \mathrm{~F})$ and a 4-break two-step process $(1 \mathrm{G} 1 \mathrm{O} 2 \mathrm{~F})$ have both been observed. The expected predominance of a 3-break process was confirmed, which accounted for $\sim 50 \%$ of the cases in recent large series $(5,6)$. However, a significant minority of cases with a 4-break two-step process was regularly seen $(1,5,6)$. The incidence ranged from 6 to $21.4 \%$. The same observation was also evident in the present study $(2 / 12$, $16.7 \%$ ). As expected, a 4-break process was detected in cases showing a classical $t(9 ; 22)$ stemline (as Case 12 in the present study). Notably, it was also found in patients with a single abnormal clone showing variant translocation (as Case 11 in the present study). This suggests that a 4-break mechanism can also operate at the initial stages of leukaemogenesis, either as a one-step 4-break process or with a second translocation between $\operatorname{der}(9) \mathrm{t}(9 ; 22)$ and a third partner chromosome occurring shortly after $\mathrm{t}(9 ; 22)$ in the same leukaemic stem cell. These 2 scenarios are expected to be rare compared to a simpler 3-break process. Therefore, the resulting 4-break DFISH pattern was less commonly observed in most series. We recently reported a similar case of the unusual 4-break process in a patient with acute promyelocytic leukaemia and a single abnormal clone of $47, \mathrm{XY},+8, \mathrm{t}(15 ; 17 ; 7)(\mathrm{q} 22 ; \mathrm{q} 12 ; \mathrm{q} 22)(12)$.

A major difficulty is seen when D-FISH is employed to study how variant translocations arise in CML. It is not 


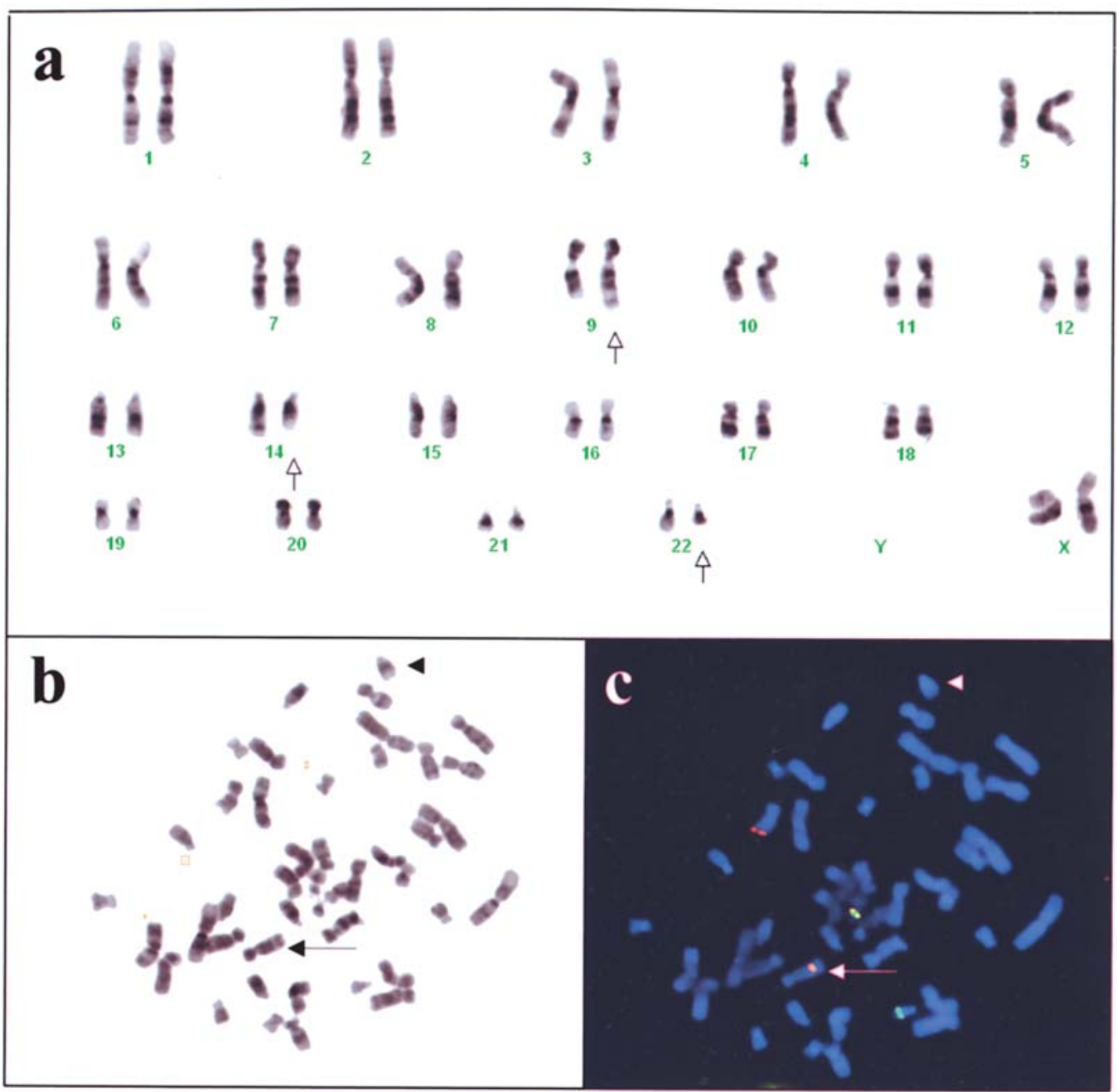

Figure 1. Aypical D-FISH pattern in Case 12. (a) Complete karyotype showing 46,XX,t(9;22;14)(q34;q11.2;q24). (b) D-FISH analysis on a relocated G banded metaphase with $1 \mathrm{G} 1 \mathrm{O} 2 \mathrm{~F}$. An $A B L-B C R$ fusion signal is detected on der(9) (arrow), indicating a second break at $9 \mathrm{q} 34$ telomeric to the $A B L$ breakpoint. No signal is seen on der(14) (arrowhead).

applicable to cases with der(9) deletion as one cannot deduce whether a 3-break or 4-break process has occurred before the deletion. This has been an important confounding factor as der(9) deletion was observed in an average of $40 \%$ of cases in most reported series (6). In the largest series reported to date, Reid et al (5) detected a frequency of 3-break and 4break process in 52 and $11 \%$ of 54 patients with variant translocation, respectively. However, a significant $37 \%$ of the patients showed a der(9) deletion by D-FISH and thus a translocation mechanism could not be assigned. As proposed by Huntly et al (9), each recombination at $\operatorname{der}(9 q 34)$ should have a finite probability leading to deletion around the region. It is therefore reasonable to postulate that many, if not the majority, of those cases with der(9) deletion had a 4-break translocation. This would be in agreement with the finding that in series with a low frequency of der(9) deletion (1) including the present one, a much higher rate of 3-break events was seen (83 to 94\%). The suggestion that a 4-break mechanism can also operate at the initial stages of leukaemogenesis and thus predisposes to deletion, as discussed above, is also consistent with the many evidences favouring a $9 \mathrm{q}$ deletion event occurring at the time of formation of the $\mathrm{Ph}$ translocation (13).

The reason for the possible difference in rates of a 4-break event among different series that might have explained the observed variation in frequency of $\operatorname{der}(9)$ deletion is not apparent. An ethnic genetic difference cannot be excluded. A similar low rate of der(9) deletion $(13.7 \%)$ was also reported in a cohort of Chinese CML patients with variant translocations (14). However, the rate of a 4-break event was not shown.

Three reported breakpoint hotspots in a third partner chromosome (14q32, 17q25, 1q21) (2) were observed in our cases. In addition, 2 cases each with breakpoint at $5 \mathrm{q} 31$ and $10 \mathrm{p} 13$ were found, which have not been found previously as breakpoint hotspots. These breakpoint hotspots are located preferentially in the GC-richest regions of the genome. GCrich regions have high densities of genes and repetitive Alu sequences. They also coincide with open chromatin with high transcription activities. These elements may increase the chance of chromosome breakage and repair or the juxtapositioning of Alu-rich sites, resulting in chromosomal recombination and translocation (2).

In conclusion, complex variant translocation in CML occurs more often as a 3-break single-step process with no reciprocal $A B L-B C R$ fusion. On the other hand, a 4-break event is also regularly observed during the initial stages of leukaemogenesis. Although by itself it may not have a 
prognostic implication, a 4-break process likely predisposes to $\operatorname{der}(9)$ deletion which is a strong predictor of survival. The observed low frequency of der(9) deletion among Chinese CML patients with variant translocations can be due to a low rate of a 4-break event. Further studies confirming and explaining this difference are warranted in order to have a better understanding of the pathogenesis of CML.

\section{References}

1. Aoun P, Wiggins M, Pickering D, Foran J, Rasheed H, Pavletic, SZ and Sanger W: Interphase fluorescence in situ hybridization studies for the detection of $9 q 34$ deletions in chronic myelogenous leukemia: a practical approach to clinical diagnosis. Cancer Genet Cytogenet 154: 138-143, 2004.

2. Fisher AM, Strike P, Scott C and Moorman AV: Breakpoints of variant 9;22 translocations in chronic myeloid leukemia locate preferentially in the CG-richest regions of the genome. Genes Chromosomes Cancer 43: 383-389, 2005.

3. Yehuda O, Abeliovich D, Ben-Neriah S, Sverdlin I, Cohen R, Varadi G, Orr R, Ashkenazi YJ, Heyd J, Lugassy G and Ben Yehuda D: Clinical implications of fluorescence in situ hybridization analysis in 13 chronic myeloid leukemia cases: $\mathrm{Ph}$-negative and variant $\mathrm{Ph}$-positive. Cancer Genet Cytogenet 114: 100-107, 1999.

4. Calabrese G, Stuppia L, Franchi PG, Peila R, Morizio E, Liberati AM, Spadano A, Di Lorenzo R, Donti E, Antonucci A and Palka G: Complex translocations of the Ph chromosome and $\mathrm{Ph}$ negative CML arise from similar mechanisms, as evidenced by FISH analysis. Cancer Genet Cytogenet 78: 153-159, 1994.

5. Reid AG, Huntly BJ, Grace C, Green AR and Nacheva EP: Survival implications of molecular heterogeneity in variant Philadelphia-positive chronic myeloid leukaemia. Br J Haematol 121: 419-427, 2003.

6. Gorusu M, Benn P, Li Z and Fang M: On the genesis and prognosis of variant translocations in chronic myeloid leukemia. Cancer Genet Cytogenet 173: 97-106, 2007.
7. Sinclair PB, Nacheva EP, Leversha M, Telford N, Chang J, Reid A Bench A, Champion K, Huntly B and Green AR: Large deletions at the $\mathrm{t}(9 ; 22)$ breakpoint are common and may identify a poor-prognosis subgroup of patients with chronic myeloid leukemia. Blood 95: 738-743, 2000.

8. Cohen N, Rozenfeld-Granot G, Hardan I, Brok-Simoni F, Amariglio N, Rechavi G and Trakhtenbrot L: Subgroup of patients with Philadelphia-positive chronic myelogenous leukemia characterised by a deletion of $9 \mathrm{q}$ proximal to $\mathrm{ABL}$ gene: expression profiling, resistance to interferon therapy, and poor prognosis. Cancer Genet Cytogenet 128: 114-119, 2001.

9. Huntly BJ, Reid AG, Bench AJ, Campbell LJ, Telford N, Shepherd P, Szer J, Prince HM, Turner P, Grace C, Nacheva EP and Green AR: Deletions of the derivative chromosome 9 occur at the time of the Philadelphia translocation and provide a powerful and independent prognostic indicator in chronic myeloid leukemia. Blood 98: 1732-1738, 2001.

10. Kolomietz E, Al-Maghrabi J, Brennan S, Karaskova J, Minkin S, Lipton J and Squire JA: Primary chromosomal rearrangements of leukemia are frequently accompanied by extensive submicroscopic deletions and may lead to altered prognosis. Blood 97: 3581-3588, 2001.

11. Wan TS, Ma SK, Ho MY, Chan LC, Yip SF, Wong LG and Yeung YM: Cytogenetic biclonality in polycythemia vera: unusual and unrelated clones. Cancer Genet Cytogenet 131: 86-89, 2001

12. Wan TS, So CC, Hui KC, Yip SF, Ma ES and Chan LC: Diagnostic utility of dual fusion PML/RARalpha translocation DNA probe (D-FISH) in acute promyelocytic leukemia. Oncol Rep 17: 799-805, 2007.

13. Reid AG and Nacheva EP: Genesis of derivative chromosome 9 deletions in chronic myeloid leukemia. Genes Chromosomes Cancer 43: 223-224, 2005.

14. Wu W, Xue YQ, Wu YF, Pan JL and Shen J: Study of deletion of derivative chromosome 9 in patients with $\mathrm{Ph}^{+}$chronic myeloid leukemia. Zhonghua Xue Ye Xue Za Zhi 27: 183-186, 2006. 